\title{
Planning of Educational Informatics Network (EIN)
}

\author{
Osman Çekiç*, Meltem Kuşçu \\ School of Education, Çanakkale Onsekiz Mart University, Turkey
}

Copyright $\bigcirc 2017$ by authors, all rights reserved. Authors agree that this article remains permanently open access under the terms of the Creative Commons Attribution License 4.0 International License

\begin{abstract}
Planning is a concept that takes place all throughout one's life. People plan their education, work, private lives, and careers; in other words, they plan their entire lives to achieve specific desired outcomes. Not only do individuals plan which schools they will attend, but also where they should live and which jobs they should take. Similar to life in general, one's educational career also is executed according to a plan. Although the educational planning was not based on a written text until the 1960s, the notion of education planning has existed since education itself. Technological inventions have been benefited from. Although it is seen, the differences of development of technology in every age, has not neglected to integrate the field of education. Technology has continued its development from duplicators and typewriters of yesterday to the smart boards and tablet computers of today. It is clear that future technological innovations will continue to find a place in education as they appear. The purpose of this study is to examine the planning of EIN (Education IT Network) integration via document analysis, part of the FATIH Project, to determine what problems exist in order not only to make a better educational plan, but also to emphasize the importance of having a good plan so that one may make proper use of EIN in lessons. Additionally, five ITC (Information Technology Counseling) teachers were interviewed in the study. These teachers were asked to share their ideas about the development of EIN and its integration into the subjects. The results indicate that EIN is a rapidly growing and developing application. It is additionally believed that EIN has reached such a level that can complete with the similar international applications.
\end{abstract}

Keywords Distance Education, E-Learning, FATIH Project, EIN, Informatics

\section{Introduction}

Today, desired economic and social development can be provided through planned and programmed education. Educational planning is the most important part of economic and social development. Training the qualified manpower necessitates that educational targets be clearly specified and that both educational and training activities be organized in such a manner to realize these targets [8].

Various projects have been prepared for and applied on teachers so that they do not become distanced from technology. The integration of technology into the Turkish educational system has occurred over a long term process. Between 1984 and 2013, steps were taken to include technology in education. A total of 32 projects were implemented between said years, 14 of which were in regard to infrastructure whereas 18 focused on extending current facilities. Among the institutions supporting these projects, the World Bank provided the greatest share of funds followed in second by the EU [15]. As a part of these projects, studies, such as Intel Education for the Future and Microsoft Cooperation in Education, were conducted in order to aid teachers and administrators improve their level of technological knowledge. The Intel program is an application providing training on digital content formation, social networks, and digital learning [14]. Benefiting from these applications, teachers and administrators serving during the time period that these training programs were offered were able to improve their technology related knowledge and skills.

Technology constitutes an indispensable part of our daily life. Whereas the technology used in education not only makes teachers' jobs easier, but it also presents students with a better equipped, more adequate educational atmosphere. Cost-benefit calculations cannot be expected to be made at the current instant as the incomes of a high cost technological change can only be determined in the long term. In this regard, what the planning is and how it shall be implemented are the aspects to be considered.

\subsection{What is Planning?}

If one of the two important processes of education and training is planning, the other is evaluation/review. Plans show us what to do, when to do it, and why it is being done. The purpose of planning in education is to render educational and training activities effectively and efficiently [8].

Planning is contemplation. To clarify, planning consists of the actions needed to be taken to move from one's current 
point to the desired point. Educational services can be better presented after having undergone some sort of educational planning. Equality of opportunity can be provided and desired reforms can be instituted. The principles of educational planning are: integrity, continuity, measurability, reliability, prudence, and simplicity. Plans must have internal integrity. Continuity is of great importance in eliminating deficiencies. Planning targets must be measurable so as to observe improvement. Working with correct data is essential in regard to ensuring reliability. Scarce resources must be used correctly and reasonably. Planning must be succinct and to-the-point as it requires expertise [9].

As also understood from the definitions, planning is a serious matter requiring expertise. The efficient use of resources is even more important in educational planning because the matter at hand is training human beings. Since educators and educational systems aims to improve the quality of life for all human beings and since the future of a country is in the hands of young generations, the constituents must be educated and resources be used in the best possible manner for a country to precipitate progress and development. Such progress and development is only possible when educational planning is undertaken in the most excellent of ways. The planning of technology use in education has taken on a new dimension with the recently instituted, oft-discussed FATIH project. Introduced in 2010 and envisioned to be completely instituted by the end of 2013, the FATIH project was seen to be left only at the middle school level as of end of 2014. Picking up speed in 2015, interactive boards continued to be installed in secondary schools and it has been decided that tablets will no longer be distributed to primary school students. Despite the disruptions experienced during the planning phase, currently the FATIH project is developing very rapidly. A comparison of the current state of affairs with the project's initial form shows just how open to improvements the project is. This is particularly true when looking at the program's Education IT Network (EIN), which houses the content to be used by teachers in students as part of the project.

\subsection{Planning of the FATIH Project}

Implemented by the Ministry of National Education (MoNE), the project is supported by (i) the Ministry of Transportation, (ii) the Ministry of Science, Industry, and Technology, (iii) the Ministry of Economy, (iv) the Ministry of Finance, (v) the Ministry of Development, (vi) the Secreteriat of the Treasury, and (vii) TÜBİTAK [8]. As defined in the projects' official site [17], it is aimed through the implement of the FATIH project to ensure the equality of opportunity in education and in training and to improve the technology in Turkish schools. Also part of the project's plan is to provide interactive boards and a reliable web infrastructure so that technology may be used in classrooms in a way that effectively stimulates students' senses. At the same time, by distributing tablet PCs to students and teachers, though now partially dropped from implementation, it was envisioned that classroom lectures would become more interactive. Seeking to promote a more effective use of available infrastructure, in-service training programs for teachers constitute another aspect included in the plan, and teachers are expected to create their own educational e-content. When all of the phases are brought together, five main components appear. As stated on the official website of the FATIH project, these components are:

- Installing hardware and software infrastructure,

- Providing and managing educational e-content,

- Using computer technology effectively in training programs,

- Providing in-service training programs for teachers, and

- Ensuring the conscious, safe, manageable, and measurable use of computer technology.

Implemented by MoNE and supported by the Ministry of Transport, the FATIH Project was planned to have been completely implemented in a total of five years. During the first year, it was to be completely implemented into high schools; during the second year, it was to be introduced into middle schools; and during the third year, primary schools were envisioned to be completed. Specifically, the project sought to; (i) complete the necessary infrastructure, including the necessary hardware and software, (ii) create the necessary e-content, (iii) update teachers' guidebooks, (iv) conduct in-service training programs for teachers, and (v) identify what is needed so that students use computer technology and the internet in a conscious, reliable, and manageable manner. As of 2016, tablets were no longer to be distributed in primary schools with trainers in the FATIH introductory courses stating that $7^{\text {th }}$ and $8^{\text {th }}$ grade students would be given priority in receiving tablets.

The five steps arranged within the scope of the project constituted the main titles forming the project's backbone. In this respect, the main titles mentioned must be analyzed one by one [18]:

Component 1: Hardware Infrastructure Improvement: Within this scope, a laptop computer and projector would be provided to all classrooms $(620,000$ classrooms $)$ of all pre-school, primary, and secondary state schools in Turkey. An intelligent class equipped with at least one multi-purpose photocopier, interactive board, document camera, and microscope camera will be established in each school. Furthermore, distance in-service education centers will also be set up in every province, amounting to a total of 110 centers.

Component 2: E-Content Provision and Management: Electronic content of an ancillary nature would be made available in compliance with courses' curriculum. E-Content was to be composed of learning objects and smart e-books supported by a variety of multi-media components, such as audio, videos, animation, presentations, photographs, pictures, and drawings. Teachers and students would be able to access e-content both on-line and off-line through web based media. 
Component 3: Effective Use of CT in Training Programs: Teachers' guidebooks were to be revised so as to include the effective use of hardware infrastructure and educational e-content provided to school classrooms.

Component 4: In-Service Training for Teachers in Classroom Use of CT: Both face to face and distance in-service training activities aiming to improve roughly 600,000 teachers' competencies would be organized so that they may make effective use of the hardware, e-content, and teachers' guidebooks available.

Component 5: Installing Network Infrastructure and Broadband Internet and Instilling Conscious and Safe CT Use: Broadband internet access would be provided to every classroom via cable. The required hardware and software were to be set up and the necessary regulations instituted to ensure that students use the internet and computers in a conscious, safe manner for educational purposes.

The purpose of the project was defined on its official site [17] as: It is targeted that CT supported education be realized through the provision of $\mathrm{CT}$ tools in classrooms by the end of 2013 in conformation with the objectives delineated in the Development Plans, Strategic Plan of [Turkey's National] Ministry [of Education], the CT Policy Report, and the Information Society Strategy Document that was produced as part of the e-Transformation Turkey project, which also defined the actions that must be taken for Turkey to become an information society.

The justification of the project was defined on the official site of FATIH Project [17]. The justification was based on a strategy document named Information Society Strategy (2006-2010) (ISS) prepared by the State Planning Organization in relation to the use of informatics technologies in the Turkish education system. The strategy document stated that: Information and communication technologies will be one of the main tools in the education process and the effective use of these technologies by the students and teachers will be ensured. In line with this, it was requested that the Ministry of Education (i) complete the infrastructure necessary to access information and to allow for user to communicate with each other in organizations where formal and informal education is given, (ii) provide students with the necessary competences so that they may make use of information and communication technologies at these locations, and (iii) develop education programs supported by information and communication technologies. In the Information Society Strategy, it is also requested the Ministry of Education to realize the objectives listed below to transform society into an information society. More specifically, the Ministry of Education was responsible in:

- Forming an adequate network and ensuring the development of e-content to promote individuals' self-development following a life-time learning approach through e-learning,
- $\quad$ Ensuring that every student who has graduated from middle school has the necessary competencies to use basic information and communication technologies,

- Ensuring that two of every three people utilize e-educational services through effective internet use,

- Presenting everyone the opportunity to learn and use information and communication technologies,

- Ensuring that one of every two people is an internet user, and

- Rendering the internet into a soft medium for all segments of Turkish society

\subsection{EIN Component of FATIH}

A website has been established under the name Provision and management of educational e-content and constitutes the second phase of the FATIH Project. The Education Informatics Network (EIN) designed by the Innovation and Education Technologies General Directorate has been introduced as a social platform where users can find safe, grade appropriate e-content that has undergone review. EIN [16] is a social education platform designed for everyone involved in education and in particular for teachers and students that aims to:

- Present a variety of rich educational contents,

- Ensure the use of computer technology in education by popularizing it,

- Respond to users' content needs,

- Exchanging information through the social network structure,

- Contributing to courses with its rich and continuously expanding archive,

- Restructuring information while at the same time learning and producing new information from previous information,

- Involving students with different learning styles (i.e. verbal, visual, numerical, social, individual, and audial learning),

- Prompting teachers to undertake cooperative education by bringing them together on a common platform, and

- Using technology not as a goal but as a tool.

In a speech at the New EIN Introduction Meeting in the city of Eskişehir, Nabi Avc1, the minister of national education, stated in regards to the EIN applications that had originally been set forth as a trial but that are now being developed following teachers' acceptance and support [11]:

What we are telling our teachers is not only how to use this; we are showing them how they can contribute to it being productive. At the beginning, our teachers started in a casual, nonprofessional manner. They entered EIN and seeing the material there, thought that they could do it and using amateur cameras, went on to produce recordings in their own classes. Then they uploaded their results here. When we saw this interest and potential in our teachers, we decided to prepare more professional opportunities for our teachers. To achieve this, we are setting up 13 studios in 12 centers across 
Turkey and preparing locations where our teachers can produce under professional conditions. We are providing not only the infrastructure but also education on content production techniques. We are expecting a big boom from this.

Avc1 also stated:

There is absolutely no more need for our teachers and students to make their parents buy ancillary course material or books, for these will be a burden to them. All kinds of ancillary materials, exercises, test examples that might be needed by our teachers and students at the beginning of each school year may be found on EIN at higher quality. If any ancillary course material is required by our students, EIN will provide even better solutions [11].

\subsection{Analysis of EIN Content}

While planning related to EIN was present in the official site of FATIH Project, it should be asked whether this planning achieves its intended goal. By analyzing EIN's official site, it could be determined whether or not it reached its goals.

EIN's site did not become fully functional until the end of 2015. Due to the site's disorderliness and other insufficiencies, there are only a few members on it. Included on the main page of the old site were the following menus: news, e-content, e-magazines, e-books, videos, audio files, visual files, e-documents, and let's discuss. In the middle of the page, one could access development tools, the EIN blog, EIN files, Distance Education Center (UZEM), EIN resources, and EIN course titles. It was also possible to find materials prepared for teachers and students. The content of the course books used in schools were also included on the site. Under the discussion tab was a forum on which teachers could express their ideas. In an attempt to increase interest, the contests EIN line and EIN were also included; and notices were sent to all teachers and students to make them aware of the website and to encourage them to become members. Before undergoing near complete renovation in 2015, the last thing to be added to EIN's site was the application scratch. Since the first version of EIN's site did not sufficiently meet expectations, it remained behind private sector competitors.

The EIN site witnessed a fundamental change with its second version launched September 8, 2015. Its disorganized content was collected under three main titles: EIN Course, Share, and Portals. Moreover, by cooperating with private sector applications, EIN's new website managed to incorporate Vitamin and Morpa. Furthermore, the English learning application, DynEd, was integrated into EIN as part of EIN Course, and such operations as branch updating and the assignment of teachers to classes were arranged in such a manner that could be tracked over EIN. Registration to and the creation of Support and Training Courses (STC) started to be offered through EIN. Directives were sent to schools assigning passwords to all teachers and students in an attempt to motivate them to use the EIN course application on their interactive board and tablets, and MoNE began to track teachers' and students' access to EIN. It was decided to assign an Informatics Technologies Guiding (ITG) Teacher to all FATIH schools regardless of whether or not infrastructure had been completed. As part of their basic duties, ITG teachers were to (i) introduce EIN Course to teachers, students, and parents, (ii) promote EIN Course, (iii) ensure that EIN Course could be accessed by all teachers and students, (iv) ensure the proper operation of the V Class application at schools where tablets had been distributed, (v) fill out forms with teachers in regard to their in-class use of EIN.

In an effort to encourage teachers to prepare their own materials on EIN, a special sub-title for content creation was designated under which the following tools could be accessed: Content Management System, EIN Presentation, Ideal Studio, the Etudyo tool for Content Development, and Xerte Online Content Development. Although these otherwise very user friendly development tools had yet to reach their desired levels of ease, it was thought that teachers would be able to use these applications more and more effectively as they became increasingly accustomed to them.

\subsection{Planning of EIN and its Integration into Course Content}

Before analyzing the actual planning behind EIN and instead look at planning stages, EIN was observed to progress through the follow process: assessment of the current state of affairs, future predictions, assessment of proposed recommendations, budgeting, reporting, approval, application, and evaluation [9].

Assessing the present state of affairs is the first step in planning, and it is during this step that the required man power and resources are specified. In short, a portrait of the existing state of affairs is presented [9]. On the official site of the FATIH Project, the General Directorate was assigned the following duty: Strategic Target 14.1: Ensuring the utilization of informatics technologies by all the schools and organizations affiliated with [the Turkish National] Ministry [of Education] in order to eliminate differences between regions by the end of year 2014. . Surveys conducted by Akınc1, Kurtoğlu, \& Seferoğlu [1] regarding the FATIH Project and EIN revealed that its objectives were in-line not only with the those actions prescribed in the Information Society Strategy Document created as part of Vision 2023's e-Transformation Turkey but also to the actions taken as part of the Development Plans, MoNE's Strategic Plan, and IT Policy Report. However, the fact that no document has been released concerning the project and the project's lack of transparency may cause the public to perceive the project in a negative light. For these reasons and due to the lack of

1 Stated in the first strategic target of the $14^{\text {th }}$ Strategic purpose included under the theme of Development of Organizational Capacity in the 2010-2014 Strategic Plan 
planning and consultation with stakeholders, with the political authority presenting it in such a way as if to garner votes in the upcoming election, a number of doubts have raised about the project. These surveys indicate that the idea exists that this project is being launched without any consideration or assessment of the current state of affairs.

During the subsequent stage, not only were future predictions made so that a scenario to achieve the desired outcomes may be constructed, targets are also clearly defined [9]. When looking at the plans, it was observed that the targets had been clearly defined on the official site of the FATIH Project [17] as: It is targeted that CT supported education be realized through the provision of CT tools in classrooms by the end of 2013 in conformation with the objectives delineated in the Development Plans, Strategic Plan of [Turkey's National] Ministry [of Education], the CT Policy Report, and the Information Society Strategy Document that was produced as part of the e-Transformation Turkey project, which also defines the actions that must be taken for Turkey to become an information society. Planned to be completed in three years, the project aims to meet these requirements by preparing e-content and by effectively utilizing interactive boards and technology in instruction. Since the protocol's signature in 2010 , the distribution of tablets in primary schools has been abandoned. After initial indecision regarding tablet distribution in middle schools, it was decided that tablets would be disturbed to $7^{\text {th }}$ and $8^{\text {th }}$ grade students. Yet, that tablets were being sold on a number of websites did not escape students' attention, and it was discovered that there were even some students selling the tablets that had been given to them by the government. The Ministry [of Education] took measures in response to this, deciding to impose a penalty for students. As for EIN, teachers preferred to use the resources available on private websites to those on EIN's first version due to its lack of organization and content. EIN's second version, however, made considerable progress in this vain.

Assessing and deciding on which recommendations to implement encompasses those actions required to progress from the current state to the targeted state. It is in this stage that risks, obstacles, and uncertainties are specified [9]. The most important obstacle to the successful implementation of the FATIH project is the complete absence of or the existence of an unreliable internet connection in classroom. No connection means that neither interactive boards nor e-content can be used effectively. In order for the project to succeed, the FATIH project must therefore be implemented in coordination with all stakeholders, with teachers being at the top of the list as the most important of these stakeholders. Teachers' interests, needs, and competences must be taken into consideration, for it is expected that even a senior teacher who has never used a computer before use the interactive board and e-content. Although e-content is supposed to be developed, a professional software team has yet to be composed, and although teachers have received in-service training, just how effective the training was has yet to be assessed. For the above listed reasons and since neither the materials available on EIN nor those created by truly competent teachers were able to be utilized to their fullest potential, it can be said that this specific planning phase was not fully benefited from. Particularly during 2015-2016 academic year, ITG's were expected to submit various forms about those teachers using EIN Course. Among one of the deficiencies found was that the interactive boards were unable to be used due to schools' inadequate electrical infrastructure [16]. Although teachers working in schools without a reliable internet connection should not be expected to use EIN course during classes, some teachers were observed trying to use the interactive boards by making their personal cellular phones into a temporary wireless modem. Yet, the project should ensure that teachers need not make such extreme efforts for its success.

After having assessed and determined which of the proposed recommendations are to be implemented, a budget must be constructed so that the plan's objectives may be realized. Sufficient funds should be allocated as needed; for if one aspect receives insufficient funds, it runs the risk of not coming to fruition [9]. According to the 2014 ERI report for Sabanci University [15], the MoNE implemented a large number of e-transformation projects that combine education management, presentations, assessments, and information processing technologies. That the development and completion of these projects had a budget of $€ 1.4$ billion (Turkish Liras) for only the year 2014 is of great significance in regard to the effective use of resources and final implementation. It can be said that the budget allotted by MoNE in 2014 and the manner of sharing the FATIH Project with public was not enough to implement all the components of this enormous e-transformation of the education system. It was reported that of the total $€ 700$ million allocated by MoNE in 2014, £300 million were appropriated for interactive boards. It was stated in the same report that the distribution of tablets to more than one million students and 100 thousand teachers in 2014 would cost $€ 520$ million alone. As such, whether the resources allocated by MoNE for in-service training have been sufficient for teachers and students to receive this e-transformation in an equipped manner or not should be reevaluated. The report found that the ratio of total resources allotted for direct in-service training to non-equipment investments and activities was 3\% in the FATIH, EIN, and e-transformation projects. However, it was also stated that the amount of money that the equipment budgets allotted to in-service training could not be tracked [18].

Reporting means to put a plan into writing before implementing it. For the FATIH Project, reports generally use the name Education Tracking Report. In addition to Sabancı University's own ERI (Education Reform Initiative) Reports [15], various organizations and institutes issue their own reports, including as the workshop report Turkey: Informatics Platform without Handicaps - FATIH Project 
Workshop for the Disabled. ${ }^{2}$ In the reports, both students and teachers expressed improved instruction as a result. It can furthermore be said that the lack of e-content is gradually being filled with the second version of EIN.

The approval process consists of the steps through which a plan must pass and the authorities who must rubber-stamp it [9]. Though the FATIH Project, and therefore EIN, went through no approval processes, and steps taken on its behalf are supported by MoNE.

Implementation is the stage where a plan is launched. Depending on the period of time that the plan covers, objectives are attempted to be realized one year at a time [9]. In the protocol signed together with the Ministry of Transportation in year 2010, the project was planned to reach completion in three years. However, the plan was still only in its first step of implementation in 2015. In terms of EIN, while problems were experienced in its first version, EIN Course has been actively used in schools with tablets and in Support and Training Courses (STC) after the second version was launched.

During the evaluation stage, not only is the plan's implementation and the degree to which objectives were reached assessed, a value judgment is reached based on whether and to what extent the plan deviated from its original objectives. The plan must be continuously and regularly scrutinized not only to eliminate any diversions from the objectives sought to be achieved but also to adapt the plan in the event that conditions change and to set new goals once original goals are achieved. Persistence is important when evaluating a plan [9]. Ekici and Yılmaz [6] evaluated the FATIH Project in regard to its applicability, efficiency, effectiveness, effect, and sustainability. Since the FATIH Project is still in its implementation stage, no evaluation report has yet to be completed for it. If an evaluation were to be made using the already existing information, then it could be stated that EIN has made significant progress with the release of its second version.

When the content of the EIN system was being prepared, it was planned to be designed in such a manner so as to provide support for each subject. Yet, while materials related to the core courses were indeed rich, other courses became of secondary importance. As the use of EIN is directly proportional with internet use, it can be said that EIN is not used at sufficient levels in those schools without an internet connection. Taking advantage of audio-visual materials to enrich classes is an instructional approach known by all teachers. While the first version was still in use, teachers usually made use of the applications Vitamin Eğitim and Morpa. Together with the second version, teachers' most preferred applications were made available on EIN, thereby enriching the content and level of use of EIN.

EIN's website is constructed in such a way that to allow teachers to create e-content and access the materials available on it through the interactive boards installed

2 Türkiye Engelsiz Bilişim Platformu Fatih Projesi Engelliler Çalıştayı throughout middle schools as part of the FATIH Project. Visual content, including videos, prepared by both teachers and the private sector are used to enrich course content. However, the absence of a reliable internet connection in some schools decreases the interactive boards' efficiency, and there are also a number of teachers who choose not to use interactive boards in their classrooms. If the content available is not presented to students in class, it can then be said that the benefits offered by EIN are of no use. In short, EIN will be a waste of time, effort, and resources if it remains unused by teachers. Furthermore, if EIN is unable to be used on interactive boards, planning will not have run its proper course, causing further waste by the private sector as a result of their content, such as Vitamin Eğitim and Morpa, going unused. It is for this very reason that studies to endorse and promote EIN are being conducted. However, despite the fact that the e-content is designed to be implemented by teachers, these endorsements may have litter or no effect if not for the support of professional software experts.

EIN has made the greatest amount of progress by integrating EIN course into classes. The $V$ Class application was developed to ensure the effective use of EIN class in those schools where tablets have started to be used, allowing teachers to teach at their own pace. Teachers can send the documents present in their tablets to either the interactive board or students' own tablets. This way, not only can teachers assign homework from inside EIN Class, they can also administer tests over tablets. Supporting other courses in addition to core courses will help to improve the richness of content available on EIN.

\subsection{Problems Faced during EIN's Planning}

Aktaş, Gökoğlu, Turgut, \& Karal [3] listed the following reasons for teachers' doubts and hesitations concerning FATIH and EIN: (i) technical support problems, (ii) classroom management difficulties in crowded classes, (iii) the lack of internet in every school, and (iv) frequent failure of technological devices. In the aforementioned study, it was concluded that teachers' insufficient technological knowledge affected the project's success. It was further observed that teachers were reluctant to have students use technological devices as they feared technical failures. Also in the same study, when students attending village schools are considered, it was remarked that not only would the current inequality of opportunity between rural and urban schools increase, it would be even more difficult to provide for equality of opportunity. Teachers of some middle schools were also observed to face difficulties due to their tablets not being compliant with the interactive boards, which might increase teachers' prejudices toward using technology in the classroom.

Obtaining similar findings to Aktaş et al. [3] in regards to teachers' capabilities, Yıldız, Sarıtepeci, \& Seferoğlu [13] concluded that important deficiencies existed in teachers' in-service training programs with respect to ISTE (International Society for Technology in Education) 
standards. In the aforementioned study, the authors expressed that the disruptions caused by electrical infrastructure problems negatively affected the teachers. Namely, it has been made known either by media or by teachers themselves that the interactive boards were unable to be launched due to the lack of a grounded socket in some classrooms.

Obtaining findings in the opposite direction to those of both Aktaş et al. [3] and Yıldız et al. [13], Akgün \& Kocaoğlu [2] found teachers to defend in-service trainings given as part of the FATIH Project, stating them to be sufficient. The aforementioned study found that while employees older than 41 had lower self-sufficiency levels than those under 41 years of age, no significant difference was observed in regard to gender. Altın and Kalelioğlu [4] concluded that although teachers found neither the tablets provided nor the content available on EIN as sufficient, they did find the interactive boards to be efficient. Günbayı and Yörük [7] compared administrators and teachers in their study, finding that administrators were more likely to hold positive opinions toward the FATIH Project and its applications than were teachers.

EIN is looking forward with greater hope now that members have increased, and continue to increase every day, after the launch of its second version. Although teachers share the materials prepared by themselves over EIN, a professional software team has yet to be formed. The absence of a professional, effective, and competent software team at MoNE is one of the biggest deficiencies in the field of education in Turkey. However, it was thought that EIN would close this gap.

The single most significant problem experienced in relation to the FATIH project was technological shortsightedness. Due to the massive size of the project and the amount of funds required to finance it, the project remained caduceus. The private company providing technological support came on the verge of bankruptcy, and different ways to resolve this deficiency were researched. One way to resolve this issue was to make a new contract with a different company. Teachers complain about the insufficiency of the e-content related to their specific courses as there are still teachers who find even the content available on the second version to be insufficient. Teachers working at schools with a high number of students were most likely to express that the materials available on the second version remained inadequate.

\section{Materials and Methods}

The current study has examined the planning of EIN, as it constitutes the e-content component of the FATIH project. The literature was reviewed using qualitative research via a document analysis. A literature review is a search scanning for studies sharing similar results to the one being conducted [5]. Finally, consistency between planning principles and stages was determined using content analysis. Deficiencies in the planning process were determined using the planning principles as the main framework. In the second stage of the research, five ITC (Information Technology Counseling) teachers were interviewed. Information about EIN was requested from FATIH educational trainers during interviews. A total of five trainers were interviewed. During the interviews, participants were asked ten questions about EIN. Questions were prepared after researching the subject via a through literature review and after consulting experts for their opinions. In addition to the document analysis the reason for having preferred using interviews in the current study is to obtain meaningful insight about EIN. Since trainers of Informatics Technologies Guidance Teachers have deep knowledge on this particular subject, they were asked open ended questions about EIN, rendering it possible to obtain quality information on the subject in question from field experts. These five teachers were involved and was trained in developing the EIN content. Pseudonyms were used and participants were referred to as "P(number)".

As a part of FATIH Project the Ministry trained teachers to coordinate the activities in each province. These teachers were selected via an exam and as of 2012, there were 420 coordinator teachers nation-wide. Of these teachers the ones assigned to school districts classified as trainers (trainer information technology counseling teachers) and required to participate in in-service education programs about FATIH Project [19]. The teachers assigned to schools were classified as school information technology counseling teachers. The interview participants consisted of five trainer ICTs; two of whom were in the province and three of whom were came from three different cities (each ICT was responsible for a city district) . All participants were male, because there were any female ICTs in the province at the time of the interviews. The descriptive information about the participants is presented in table 1 .

Table 1. Participant Information

\begin{tabular}{|c|c|c|c|c|}
\hline Participant & Age & Length of Service & Field & Location \\
\hline P1 & 33 & 10 & Information Technology & Province \\
\hline P2 & 35 & 12 & Information Technology & Province \\
\hline P3 & 48 & 24 & Physics & City1 \\
\hline P4 & 44 & 22 & Machine Design and Construction & City2 \\
\hline P5 & 42 & 19 & Science Education & City3 \\
\hline
\end{tabular}


These teachers were asked to share their ideas about the development of EIN and its integration into the subjects. Interviews are a way to collect data and although they are usually conducted face to face, they can also be made by telephone or instantaneous audiovisual transmitters. Moreover, motion communication with hearing and speaking impaired individuals is also considered to be a form of interview [10]. Interviews are among the most commonly used data collection techniques in qualitative researches due to their effectiveness in benefiting from individuals' experiences and opinions. Interview participants have the opportunity to express themselves more comfortably as they verbally convey their opinions [12].

\section{Findings and Comments}

Upon analysis of EIN, it is observed to have attained its goal to form and share e-content. It was envisioned that trough EIN; education activities would be enhanced and teachers' instructional efforts would be supported by sharing materials developed by either teachers themselves or the private sector to be used on interactive boards. An analysis of the literature shows that although teachers who use the interactive board in their classroom were satisfied with EIN, they stated that the e-content available on it was inadequate. When the objectives defined in EIN's planning were analyzed, it is observed that all of the nine items specified were achieved at various levels; some at a low and others at a high level. The greatest deficiency in regards to the achievement of the goals is related to e-content quality. Concerning knowledge production, teachers generally prefer to use finished materials no matter how simple content creation materials on the site are. As of yet, it can be said that objectives have not been reached to the desired level. The intended level will be reached when teachers share and use technology as a tool rather than a goal.

The findings gleaned from the interviews conducted with instructional trainers included in the second part of the study are evaluated below. Responses to a total of 10 questions were asked to each of the five participants.

\section{Question1: What are the objectives and policies related to EIN's integration into education?}

Four of the participants responded to this question in terms of its relation to the FATIH project, emphasizing that the objectives outlined in the FATIH Project compose one part of the overall movement to increase opportunities and to improve technology. Not only did participants express that both synchronous and asynchronous education opportunities could be achieved through the use of EIN, they also agreed that content was strengthened in such a way to benefit both teachers and students as a result of the materials prepared by teachers or obtained through agreements with other education platforms.
In response to the first question, P2 expressed the following:

When thinking about just what the goal of integrating EIN into education is, it should be remembered that this goal falls under the umbrella of the FATIH Project and that EIN has been established to realize this goal. More specifically, [EIN] aims to increase the educational efficiency through the opportunities it provides together with the Movement to Increase Opportunities and Improve Technology. Through government funds, the required equipment has been provided to schools, the EIN platform has been established, and the free use of content either created by teachers or acquired through agreements with a variety of educational platforms has been made possible.

Looking at the subject from the same point of view but offering a different opinion, $\mathrm{P} 4$ expressed the following:

As part of the FATIH Project not only is it envisioned that a national archive as well as policies facilitating access to be created, teachers will be able to share with other centers of education around the world. EIN is constantly being supervised, allowing it to be used in a more secure manner, protected from both viruses and hackers. This is what makes it different from other sharing sites.

As a conclusion, policy states that the objectives of the FATIH project are to provide safe access to the same education materials to the degree possible for the sake of achieving equality and cooperation.

\section{Question2: What applications were implemented during EIN's integration process into education?}

All participants mentioned both EIN and the developments that occurred as part of the FATIH Project. Accordingly, participants stated that in addition to the installation of necessary network infrastructure, printers and interactive boards had started to be delivered to schools and that the transition to EIN occurred after the appropriate infrastructure was in place. During this transition process, not only were content development tools included, educational content and training applications were made available.

P1's comment on this subject is:

In this respect, it is necessary to mention the facilities and equipment supplied by the Ministry [of Education] and supported by the government. Hardware, such as printers, interactive boards, network infrastructure, fiber internet, tablets, and computers have all been provided to schools. Furthermore, the EIN platform is made up of educational content and can be considered a social education platform still under developed and open to innovation. All content, be it audio, visual, or any other kind of items shared are supported by EIN. In this respect, the required hardware have been provided to many schools and the teachers at these schools have received face-to-face training that continues to be supported through the distance learning programs. EIN 
Class has transformed into a medium over which you can send homework and worksheets to students. Even examinations, votes, and questionnaires can be made by tablets using the V Class application. Furthermore, Dyned settings can be executed through EIN.

Whereas P5 stated:

EIN Course includes a number of tools to be used to prepare online e-content whereas EIN File-though not fully functioning-may be used to share news, experiments, videos, and notices in addition to course books and other resources over a digital medium.

As a result, during the software development process that took place once the necessary hardware had been installed, content for EIN Course was the first component to be developed, after which content creation tools were updated and made easier, course books were incorporated into the electronic medium, and it was ensured that teachers understood how to make use of the new opportunities through in-service training programs. In addition, since EIN constitutes the software component of the FATIH Project and since the second version of EIN was developed very shortly after hardware was installed, it can be concluded that the first version of EIN was insufficient. As a result, it was expressed in the literature that the second version of EIN was significantly more advanced.

\section{Question3: When studies focusing on the impact of EIN's integration on education are examined, what is the magnitude of impact observed?}

All of the participants stated that while both the portal and the content were of interest to everyone involved in education, since they had not performed any analyses in regard to the magnitude of impact, they answered the question based on their own experiences. Participants cited the magnitude of impact in order to demonstrate that both students and teachers can benefit from the educational content, that teachers could share their own materials, that students and teachers could maintain continuous communication, and that both extracurricular activities and the course itself could be not only administered but also followed up on more easily.

The following are P2's comments concerning this subject: I didn't have the possibility to review the studies on this subject, but I believe that in the very near future when everything falls into place, this platform will become a worldwide example since both students and teachers can benefit from the content available on it, since teachers can share what they've produced using this platform, and since it can be used to support and facilitate student-teacher communication, homework accountability, and extracurricular activities. I believe that it be very useful if it is used correctly and for the purpose it was designed and that it will constitute a valuable system that allows us to attain significant education benefits.

Participant P5 made the following comment:

[EIN] provides more resources for teachers in their classes, allows students to easily access the homework and course materials, facilitates greater student-teacher interaction outside school, and creates awareness in some teachers, such as senior teachers who don't have a very good relationship with technology.

Approaching the subject from another point of view by evaluating the impact magnitude from the point of view of teachers, P4 commented as follows:

Although we haven't made any official reports, my observations and discussions with other colleagues is that based on hearsay, $65 \%$ of people reject the program. We don't know anything. Tracking turning to interested looks. To present interested looks and behavior. Start to apply. Ok, I can use this in my classes. I will definitely use this technology in my classes.

In conclusion, the magnitude of impact that EIN's integration has had on education according to teachers was generally restricted to new content and techniques to be used during the overall teaching process. Moreover, teachers did express negative opinions and attitudes toward certain innovations. As such, it can be stated that teachers' answers provides us with hints that a new, previously unseen dimension has been introduced in education.

\section{Question4: When criticism regarding EIN's integration process is examined, what is its magnitude?}

According to participants' answers, the main criticisms observed are: (i) the insufficient level of content despite the advances that have been made, (ii) students' reading habits having become weaker, and (iii) the incremental increase of technological dependence. On the other hand, two participants offering a different perspective critiqued the resistance shown by some teachers against technology. Participants also expressed criticism related to problems arising not only from technical infrastructure, namely hardware, but also from the software used.

P1 commented on this subject as follows:

As a teacher, the first criticism I hear is that existing trainings/questions are insufficient both in terms of content what they endeavor to instill us with. Moreover, [the program] doesn't address all branches. I mean that if this is supposed to be a platform, it should be filled with materials so that it will be useful to all branches. We face such issues as disregard to technology by teachers, technical deficiencies in the infrastructure where the content will be used, such as grounded outlets, network infrastructure, fiber internet, energy breakdowns, etc,. Insufficient content can be divided into different level groups or categories, as well as other criticism. 
In addition, $\mathrm{P} 3$, one of the trainers, made the following comment:

While the teacher is so heavily burdened with the EIN Class and V Class, hiring temporary personal from outside the school and requesting access when the content for students and teachers is not fully ready will bring even more burdens.

As a result, it is clear that there exists a group of teachers who completely reject the use of informatics technology and who are disturbed by all classes being so dependent on technology. It can be said that these issues can be resolved through the correct understanding and use of technology.

\section{Question5: How has EIN's integration into education affected the structure, operation, culture, teaching-learning processes, and human aspect (students, teachers, and administrators) of the school organization in Turkey?}

Despite the different comments made by participants, the most commonly expressed opinion is that educational and instructional activities will improve and that the achievement gap between urban and rural schools will decrease. Not only did participants mention instituting the ability to use organizations' technological facilities during non-instructional times, they also noted that the educational content available for teachers and students should be improved. They also stated that the platform enriches the learning process by providing ease in teaching and diversity in experiments.

Covering all dimensions of the question P2 made the following comments:

[EIN] is a system within the FATIH Project that has such components as interactive boards, a communication infrastructure, and tablets. There are many processes going on in the formation of this system that have to do with organization and both teachers and classes [and that will continue] until [the platform is] ready. They're trying to implement these processes during times that won't disturb education or instruction. During this period, there might be problems between the people coming to set up the platform and the school administration. We have personally witnessed such problems. The Ministry [of Education] must have also experienced the same. Once set up is completed, utilization will constitute an entirely different side of the problem. Just as there are willing teachers, there are also unwilling teachers who resist using these. What's more is that the system causes problems from time to time and what not. All this causes people to have and argue different opinions. Whether students will benefit from this platform or not depends on whether ample content is made available on it over time, whether the teacher actually uses it, and whether the Ministry integrates the required systems. Everything is interconnected with everything else. Students and teachers are asked to access the system at schools where it hasn't yet been set up. Why? Accessing a system which cannot yet be utilized by all branches and grades is of no use either to the teacher or the student. And so, it's considered to be a waste of time. And time is important for all of us. Currently, everything is related to time.

P4 replied about the educational side of EIN, stating the following:

Previously, EIN's website was considered to be an inadequate resource where you could only get information and documents and which was nothing more than a portal. With the new additions and arrangements, particularly with the addition of EIN Course and of the Content Development sections. And integrating the interactive board with EIN Course, V Class, and V Student, raised it to a more dynamic and satisfactory status. Distributing tablets to primary schools was abandoned as it was determined that the development of students' knowledge and more particularly, their skills would be adversely affected.

Offering a different point of view, P5 commented as follows:

Not only does the socio-economic structure of the geographical region of the schools in our country directly affect the quality and success of education, so does the big difference in how both families and students perceive of education. I believe that once EIN becomes fully operational, meaning its infrastructure, fiber internet, interactive boards, tablets, and e-contents, the equality of opportunity in education will improve, which will cause the opinions of students and more specifically, those of parents to change. [The platform] will ensure that the achievement gap between rural and urban schools will diminish.

In conclusion, it can be said that time is required for students and teachers to be educationally affected by the process. When the comments in regard to school culture are taken into consideration, it can be said that the project will close the achievement gap resulting from environmental and social factors and that the only issue concerning administrators is to ensure that the project's infrastructural aspects be implemented without disturbing education. For now, it can be said that the project's real impact will be observed over time as it is still an incomplete system.

Question6: Has a team been organized whose job is to prepare content for EIN? Who composes this team? Are they connected to MoNE or are they a private endeavor?

Participants expressed that a team does exist and that it is connected to the Ministry of Education. Not only did participants comment about content, they also discussed the services received from the private sector and what gains EIN would make in the future. Participants also expressed that subject based training courses for EIN were to be given based on which subject teachers taught beginning in 2016 
and that these in-service trainings sessions had already started. Moreover, participants also stated that the classes of experienced teachers had been recorded in the Ministry of Education's studios.

\section{P1 commented about this subject as follows:}

EIN used to be more confusing; but now, new sections have been created and education portals have been separated from one another. Now, acquisition based content prepared in cooperation with TTNET [Turkish Telecommunication's Internet Provider] and Vitamin Lisego have been integrated into EIN Course, which was launched together with the EIN V Class application. TTNET Vitamin is normally a paid platform, but Teachers and students at state schools can utilize the same education services free of charge through the agreement made by the Ministry [of Education].

Considering the time he had spent in the Ministry of Education, P4 shared his experiences as follows:

Yes, there is [such a team of designers]. The team, EIN Group was created and is affiliated with Yeğitek and continues to generate content. There are studios special to the EIN Group. The E-Material Library on EIN is expanded and developed by recording the classes of experienced and competent teachers in this studio. Moreover, the content designed by private companies have been purchased and made available on EIN.

Finally, P5 commented as follows:

The content available on EIN is made available through different channels. Some content has been supplied from private companies by donation or purchase, such as Vitamin contents, Morpa Campus, and Khan Academy. The Ministry [of Education] also has teachers prepare some content. Beginning in 2016, the Ministry will institute training programs for EIN based on the subject taught by teachers. Similar training programs designed to teach how to generate content have been going on since 2015. At the end of these training programs, around 150 people will be selected as administrators and commissions composed of these people will assess the content to be loaded.

As a result, it can be said that the steps taken to develop EIN will continue at a steady pace.

\section{Question7: Since when have the applications present under Content Generation been available? What can be said about the characteristics of each implementation (which are online, which are offline, what are they for, etc)?}

Participants' answers indicate that all implementations are online. The notion that teachers are able to make easy use of the applications available is also valid, with participants stating that these applications have been included on the site since EIN's first version. They also stated that these applications were EINPresent, idealStudio, Etudio, and Xerte, and that the new application developed by the Ministry of Education, CMS (Content Management System), has also been made available.

P2 commented about the subject as follows:

These applications have been around for a long time. All of them are separate platforms allowing one to create online content. All of the tools allow one to create and publish educational content online. Xerte and idealStudio were more emphasized during training programs as they have more developed tools compared to the others. It is necessary to have a good command of these systems. For example, the Ministry [of Education]'s own distance learning pro were prepared using idealStudio. Etudyo allows one to create interconnected presentations in the form of chapters or subjects. EIN Presentation is an online platform that lets one practically form presentations over EIN. Nowadays, the Ministry has already published a new content preparation system called CPS. I think that EIN makes it easier to develop acquisition based course material and content in-line with its objectives and that educational programs given after this will focus on such aspects.

Explaining the applications one by one P5 replied as: Xerte is the e-content creation tool designed for teachers. The application was prepared by Nottingham University and was made available for teachers to use on EIN after being translated into Turkish in 2014. It works online. The e-content created can easily be shared with students and other teachers. The teacher can easily prepare interactive e-content by transferring a subject in their syllabus to the digital medium. Interactive e-content increases learning and motivation in education. In ITG courses, trainee teachers have been taught how to use Xerte for 2 years. IdealStudio is an online content tool similar to Xerte. Interactive e-content can be prepared with this tool. It has more details compared to Xerte, this also makes it harder for teachers to use it. For the most part, asynchronous interactive distance learning programs are prepared using idealStudio. EIN Presentiation is a content development tool that teachers can use to prepare online presentations. It has a simple interface which can be used by any teacher. The presentations prepared on it can be saved in pdf format. Etudyo is a content generating tool where teachers can create e-content that is visually and audibly rich. It works online. The e-content prepared with it can easily be shared with students and other teachers.

As a result, the content creation tools included on EIN are applications that can be easily used by teachers of all subjects and with which they can also prepare their own educational material. However, the main factor here is teachers' willingness to prepare their own material instead of using 
already made material.

\section{Question8: What expectations does MoNE have for its teachers? Does EIN adequately fulfill its intended objectives? To what degree does it achieve its goal?}

The commonly held opinion by participants is that teachers be included in the system. Not only are teachers expected to contribute to the content, they are expected to use the V Class system in-line with its stated purpose. All of the participants remarked that although EIN is being run in-line with its objectives, it had yet to reach its full capacity.

Commenting on this subject, P3 stated, "The foundation is the teachers themselves. [EIN] is fit for use, but it's still at the start up stage. For this reason, there's a long way to go. But the steps being taken are in the right direction."

Adding depth to the subject with his opinions is P5, who stated the following:

About EIN, teachers want to immediately have an interactive board, fiber internet, a tablet, and EIN, with all of its rich e-content. I think EIN is able to reach its objectives. Gathering all of the tools that teachers and students will under a single platform has brought a new look to education that is in-line with the century we live in. We are in the information and communication age, and its information that's important in this age. EIN will be increasingly more adopted by teachers and students if it can be even more integrated with MEBBis [MoNE's informatics systems] and e-school. Besides, no matter how much EIN advances, a fast and good quality internet infrastructure is required to access content. Unfortunately, using EIN doesn't happen to be possible with the existing infrastructure in our schools. Without internet, the interactive board becomes nothing more than a television and the tablet a game tool.

As a result, it can be said that EIN is proceeding in the right direction while still having a way to go. What the Ministry of Education expects from teachers is that they be productive and use the technology correctly without resistance.

\section{Question 9: What kind of process is run before EIN is uploaded? Who assesses it?}

Four of the participants stated that the content published on the site is reviewed by a committee. One participant expressed that there is currently no assessment mechanism and that assessment will start in the future once a committee is established. One participant remarked that the content is open to likes and complaints.

Commenting on this subject P3 stated, "The portals structures known by the groups formed with admin, mod authorized people are nearly the same. Content is open to likes and complaints."

Also responding to this question, P4 stated, "Content loaded on EIN is published only after having been reviewed and approved. When two pieces of contents are of the same type, the one more compliant to the standards is preferred."

As a result, it can be said that any materials to be published on the site are reviewed before publication. In the event that any material makes it onto the site without being reviewed, it will inevitably face removal.

\section{Question10: Can you share what you would like to see added to EIN?}

Four of the participants were of the opinion that EIN is a good platform that supports education. However, participants also stated that since the project was still yet to be completed, it had not reached its full capacity and that EIN would attain its full efficiency and ability to support education once the project has been fully implemented. One participant did not give a response to this question.

P2 offered the following comment:

Generally speaking, once its deficiencies are eliminated and it is filled with right materials, it will achieve the goals it has set out to achieve. I think it will be a very useful platform both for the teachers and students and will constitute an example education platform for the rest of the world.

P3 responded, saying, "It's a grounded project with an awesome future if it can overcome its current flaws."

Finally P4 responded with the following comments:

Delays are encountered due to various technical and undesired aspects, such as in assembling interactive boards. As a result, courses are delayed since they are presented over the interactive board. Once the FATIH Project is completed, student learning will increase to higher levels.

As a result, the notion that EIN will be a promising and beneficial material resource has already established itself in in all of the participants' minds.

\section{Conclusions and Suggestions}

EIN is developed to support the FATIH Project by arranging and sharing e-content. The most important reason that e-content was unable to reach desired levels is due to the absence of a professional software development team. The main obstacle here was the human resources. The Ministry was not able to see the importance of the content but was more focused on hardware and logistics. Thus content development teams in each of the subjects should have been formed and e-content had been made available even before the distribution of hardware to schools. In this sense, the Ministry could have utilized a source it already had available. The graduates of Computer Education and Education Technology majors could have been organized, trained, and assigned to specific duties within the FATIH project and 
specifically for EIN.

Computer and Education Technologies Training Departments have been established within many universities throughout Turkey in 1998. The goal of these departments is not only to train computer teachers but also to train education technologists. Students were trained as CAE (Computer Aided Education) experts. A CAE expert is one who develops and implements the most suitable technological material for a course together with the course teacher, regardless of what subject the teacher teaches. Today, e-content formation is intended by the technological material. If the Ministry of National Education had made use of CAE experts in this project, it could have established a professional software group to prepare the most adequate materials, ensuring that much more qualified e-content be prepared. The Ministry was also the cause of resources being wasted due to its not using the resources it had on hand. Clearly, Computer Education and Educational Technology (CEET) graduates have been wasted because computer teachers have encountered problems with standards for a long time throughout the country and have been forced into being format or there are still computer teachers who must cope with the same problems. The Ministry of National Education needs a professional software development team consisting of CEET graduates. This way, the Ministry will be presented with the opportunity to close a very significant gap in the field of educational software.

In Turkey, there are students who are part of a variety of different achievement groups. These groups must be taken into consideration when EIN content is formed. The same content may be very easy for one student and very difficult for another, depending on his abilities. This will direct teachers to search for different resources again. For this reason, the content on EIN may be divided into different degrees of difficulty, i.e. easy, medium, and difficult.

After strengthening the e-content with a professional software development group, the site's presentation must be dealt with as presentation is key in regard to how effectively the site will be used. Media power must be benefited from while improving the site's presentation. For example, works to improve presentation can be made as a Public Service Announcement on EIN's website, and various incentives can be offered to increase participation as more benefit can be obtained through offering incentives to teachers and the content development team.

Another subject to be analyzed is equality of opportunity. While the FATIH Project mentions equality of opportunity, of the fact that there are students without internet, computers, and even electricity at home should not be neglected. At schools, as part of this plan, technology tutoring must be implemented and students without access to technology at home must be able to benefit from the technological opportunities of the school after school or during weekends. Even the EIN plan must be supported by other plans, such as the Schools Become Life (Turkish: Okullar Hayat Olsun) project. Planning must be strengthened by cooperating with various partners to allow students without a computer or internet at home utilize school facilities at any time of the day they want. Students must be introduced to technology through technology tutoring programs.

As a result, the FATIH Project had very good objectives. If we look from the point of view of planning, different approaches must be adopted in creating e-content for EIN. The site must also be prevented from going beyond its objectives. If content can be brought up to a consistent and rich level, the number of teachers using these materials on interactive boards will increase rapidly. Planning phases must be implemented in a more realistic manner. Planning should include clearer objectives and realistic applicability. This project is a powerful project with the potential to surpass its original target on condition that the right planning and policy is followed. However, the project itself is colossal and includes many interested and involved parties. The system had to be very well organized from the beginning, which the Ministry of Education had failed to accomplish. Furthermore, the Ministry also failed to lead the buy-in of majority of the teachers and administrators. Most had to participate without know what actually is being done or what the expected results would be. For teachers and school administrators, it was another transient policy that the Ministry instituted.

\section{REFERENCES}

[1] Akıncı, A., Kurtoğlu, M. ve Seferoğlu, S. S. (2012). Bir Teknoloji Politikası Olarak Fatih Projesinin Başarılı Olması İçin Yapılması Gerekenler: Bir Durum Analizi Çalışması, Akademik Bilişim Dergisi. Uşak Üniversitesi.

[2] Akgün, Ö. E. ve Kocaoğlu, B. Ü. (2015). Öğretmenlerin Fatih Projesi Teknolojilerine Yönelik Öz-Yeterlik İnançları, SAÜ Eğitim Bilimleri Enstitüsü, VI. Ulusal Lisansüstü Eğitim Sempozyumu.

[3] Aktaş, İ., Gökoğlu, S., Turgut, E. ve Karal H. (2014). Öğretmenlerin FATİH Projesine Yönelik Görüşleri: Farkındalık, Öngörü ve Beklentiler, Necatibey Eğitim Fakültesi Elektronik Fen ve Matematik Eğitimi Dergisi. Balıkesir.

[4] Altın, H. M. ve Kalelioğlu, F. (2015). Fatih Projesi ile ilgili Öğrenci ve Öğretmen Görüşleri, Başkent University Journal of Education, 2(1), 89-105, Ankara, Türkiye.

[5] Creswell, J. W. (2014). Araştırma Deseni Nitel, Nicel ve Karma Yöntem Yaklaşımları, Ankara: Eğiten Kitap Yayınları.

[6] Ekici, S. ve Yılmaz, B. (2013). Fatih Projesi Üzerine Bir Değerlendirme, Türk Kütüphaneciliği, 2 (27).

[7] Günbay1, İ. ve Yörük, T. (2014). Yönetici ve Öğretmenlerin Eğitimde Fatih Projesinin Uygulanma Düzeyine İlişskin Görüşleri (Antalya İli Muratpaşa İlçesi Örneği), Eğitim Bilimleri Araştırmaları Dergisi, 4 (1), 189-211.

[8] İşman, A. ve Eskicumalı, A. (1999). Eğitimde Planlama ve Değerlendirme. Adapazarı: Değişim Yayınları. 
[9] Karakütük, K. (2012). Eğitim Planlaması. Ankara: Elhan Kitap.

[10] Karasar, N. (2012). Bilimsel Araştırma Yöntemi. Ankara: Nobel Akademik Yayıncılık.

[11] TBD (2015). Yeni Eğitim Bilişim Ağı Tanıtıldı, Bilişim Dergisi, 181, s: 36- 37. Ankara.

[12] Yıldırım, A. ve Şimşek H. (2011). Sosyal Bilimlerde Nitel Araştırma Yöntemleri. Ankara: Seçkin Yayıncılık.

[13] Y1ldı, H., Sarıtepeci, M. ve Seferoğlu, S. S. (2013). FATİH Projesi Kapsamında Düzenlenen Hizmet-İçi Eğitim Etkinliklerinin Öğretmenlerin Mesleki Gelișimine Katkılarının ISTE Öğretmen Standartları Açısından
İncelenmesi, Hacettepe Üniversitesi Eğitim Fakültesi Dergisi, Özel Sayı (1), 375-392.

[14] http://egitim.intel.com/temel_bilesenler.htm, Access Date: 08.04.2016.

[15] http://erg.sabanciuniv.edu, Access Date: 16.11.2014.

[16] http://www.eba.gov.tr/, Access Date: 03.04.2016.

[17] http://fatihprojesi.meb.gov.tr, Access Date: 16.11.2014.

[18] http://www.fatihprojesi.com, Access Date: 16.11.2014.

[19] Yamamoto, G. T. (2012). Eğitimde Fatih Projesi Formatör Sorunları Çalıştayı Taslak Raporu, Future Learning 14 Kasım. Istanbul: Okan University. 